\title{
The Situation of Chinese Manufacturing Workers Under Covid-19
}

\author{
Qianying $\mathrm{Ye}^{1^{*}}$ Shiqi $\mathrm{Chen}^{2^{*}}$ Xiqi $\mathrm{Li}^{3^{*}}$ \\ ${ }^{1}$ Department of Social \& Policy Sciences, University of Bath, BATH, BA2 7AY, United Kingdom \\ ${ }^{2}$ College of Agriculture and Biotechnology, Zhejiang University, Zhejiang, Hangzhou 310058, China \\ ${ }^{3}$ Oaks Christian School, Westlake Village, 91362, United States



\begin{abstract}
The COVID-19 outbreak in China became a major public health issue. Manufacture industry in China is among many scopes that have been impacted by the pandemic. The manufacturing workers have undergone the pressure of being forced to stop work and later on resumption to work. Under this situation, their mental and social status are often ignored by people in comparison to many other groups of people. Under this circumstance, this paper is to research and analyze the social and mental status of China's manufacturing workers under the COVID-19 We used a cross-sectional survey online on 10098 participants who are manufacturing workers from Xing Group Co., LTD on their social and mental status under the COVID-19 pandemic. A pressure index was developed according to the survey. It shows that the average stress score of manufacturing workers (pressure index) is 20.337 (maximum $=49$, minimum $=0$ ), and the standard deviation is 9.28. Different self-awareness, sources of stress, income expenditure had an impact on manufacturing workers' pressure index. In this paper, several suggestions are proposed to companies and government to help them took better care of these manufacturing workers.
\end{abstract}

Keywords: Manufacturing workers, COVID-19, Chinese, Mental health

\section{INTRODUCTION}

The emergence of severe acute respiratory syndrome SARS-CoV-2 disease (COVID-19) in China at the end of 2019 has caused a large global outbreak and become a major public health issue [1]. The pandemic has a great impact on China's manufacturing industry and its workers.

According to the National Bureau of Statistics data, by the end of 2020, China's urban unemployment rate was $5.2 \%$, and the registered urban unemployment rate was $4.2 \%$. The total number of migrant workers in China has a decrease of $1.8 \%$ over the previous year. However, the consumer price for the whole year increased by $2.5 \%$ over 2020. As of this date, with the increase of consumer price and the decrease of employment, the lives of manufacturing workers in China were also impacted significantly.

It's a huge challenge for both the manufacturing industry and the manufacturing workers. Isolation from the outside world, bereavement, unemployment, and income loss all lead to the deterioration of people's mental health (WHO). By the beginning of March 2020, over $90 \%$ of China's manufacturing workers had returned to their jobs [2]. But as of April 2021, some workers are at their quarantine periods, or can't get back to work due to the epidemic prevention and control methods. Thus, employment in $78 \%$ of the factories is still at a low level [2]. Simultaneously, according to the World Health Organization, 93\% of the countries reduced or stopped providing mental health services to the people during the epidemic period (WHO), even though the demand for mental services is increasing. In such an urgent situation, people's mental health is often more ignored than their physical health. People who are neglected will have a lower sense of well-being, are more prone to depression and sleeping difficulties, and even have more chances of having mental health diseases such as depression and anxiety. For Chinese manufacturing workers who have experienced factory stoppage, resumption, and increased work pressure in the past year, their mental health is especially in need of help. 
Manufacturing workers have always played an essential role in the country's economic recovery and product supply. Nevertheless, their living conditions and mental health have often been neglected. Little research has been done on this problem, therefore we decided to fill the gap. In this research, we collected primary data through a survey on China's manufacturing workers, and searched secondary data to analyze the mental health and social status of these workers. Our purpose of conducting this research is to provide evidence-based suggestions to the government and companies, so that they can take solid measures to provide more protection for Chinese manufacturing workers' rights and interests.

\section{METHODOLOGY}

\subsection{Research Approach}

The overall aim of this research is to understand the social and mental pressure that Chinese manufacturing workers suffered from during the COVID-19 pandemic, and then to explore the reason and causes of these problems. To be more specific, this research will closely examine the changes that the pandemic brought to the workers' lives, such as the production suspension and resumption of work, and how these production challenges had put pressure on the workers.
Our primary research uses mix methods - a combination of qualitative and quantitative research. For the purposes of this research, a questionnaire was used because this is an efficient method to collect information from a large population. Besides, through the questions in the questionnaire, we used a pressure index to see the "pressure score" of the workers. Pressure Index is a numerical figure that quantifies the manufacturing workers' pressure, according to their rating for their own stress level. The higher the pressure score is, the greater their stress is. Each question response assigned a score (either negative or positive) and the pressure index is the total of the number.

To better analyze the social and mental status of Chinese manufacturing workers, we also gathered secondary data and use the narrative review in this research. All the secondary data and literature collected in this study are mainly from LSE library and Google Scholar. Organized keywords mainly include "Chinese manufacturing workers", "COVID-19", "mental health", "social" and "return to work". Other keywords such as "essential workers" and "workers" were also being used. All of the secondary data that we reviewed are from the recent two years.

\subsection{Questionnaire Design}

Staff Health Survey during the Pandemic

01 Have you ever doubts about your worth during the pandemic?

$\bigcirc$ Yes

No

02 Is this job important to you? Do you feel pressure supporting your family? OYes

No

03 During the pandemic, do you maintain a positive attitude in your life and work? Yyes No

04 Is your current salary sufficient for your family or personal expenses?

○Yes

ONo

05 Under the pandemic, did the company and government give you enough spiritual care?

OYes

ONo

Not really

06 Are you stressed by the cost of health care for you and your family? Yes, I'm very stressed

8 No

8 Not really
07 Under the pandemic, are you worried about the risk of infection you are exposed to?

Yes, I'm very stressed

Not really

No

08 In addition to the existing basis, what additional help do you expect from the company or government?

Financial help

Help in daily Life

Psychological help

09 Has your work stress increased or decreased under the pandemic?

It decreased

It didn't change

OIt increased

10 Are you satisfied from the financial subsidies from the government and company?

Yyes

ONo

Not really

11 Is the pandemic supplies provided by the company sufficient?

Not enough

Not really

OYes, very

Figure 1 Staff Health Survey during the Pandemic. 
Figure 1 shows the questionnaire design. It contains 11 closed-ended questions, of which $70 \%$ are targeted at the mental health aspect, and $30 \%$ focus on people's social situation. Each of the questions is given two to three options, including nominal data in the form of yes/no answers. The questionnaire mainly includes the following features: pressure for supporting worker's family, self-mental evaluation and attitude towards help from the company and governments. Since the study of one's self-value has a direct impact on one's mental health [3], these aspects of the question can help us assess the mental health status of the participants during the pandemic, and how this has changed.

The questionnaire was created using an applet on WeChat, and was distributed online to the participants. At the end of the survey, demographic information about the workers was collected, and is strictly kept confidential.

\subsection{Participants}

Using convenient sampling, results from 10098 Chinese manufacturing workers were collected from Xing Group Co., LTD, which has factories in Taizhou, Foshan, Xuzhou and Fushun, China.

Workers who participated in this study come from 17 different cities in China. They are $60.333 \%$ male and $39.77 \%$ female who age between $16-60$. People under high school education account for $80.07 \%$; and $77.6 \%$ of all workers are married.

\subsection{Research Methods}

In our statistical analysis, we collected workers' pressure index through the questionnaires, and treat other questions in the questionnaire as subdivisions of pressure index, which include self-value, salary, family cost, work pressure, mantle support from the enterprise and financial support from government, etc.

Statistical analysis was performed using R studio. To extract meaningful insights from the data collected, we first employed descriptive analysis (e.g. Mean, standard deviation, t-test, and linear regression model) to rank and identify the relationship among pressure index and other dependent variables.

We also treat pressure index $(\mathrm{Y})$ as dependent variable and other questions (X1, .., X10) as independent variables. A regression model was constructed to compare the coefficients of different variables and analyze the influence of different variables. The model is present below.

$$
Y=b+a 1 X 1+a 2 X 2+\ldots+a 10 X 10
$$

With this model, we can predict workers' pressure index with their answers of other questions.

\subsection{Ethical considerations}

The current study was subject to certain ethical issues.

As mentioned above, all participants are informed with the purpose of the research and all results collected are anonymous.

However, the questionnaire was distributed online via the manufacturing department heads. Therefore, the workers were required to participate in the questionnaire, and they were free to not answer or leave blank questions.

\section{PRESENTATION OF RESULTS}

\subsection{Basic information of manufacturing workers (Q1-11)}

The average stress score of manufacturing workers (pressure index) is 20.337 (maximum $=49$, minimum $=$ 0 ), and the standard deviation is 9.28 .

\subsection{Single-factor analysis of pressure on manufacturing workers.}

Figure 2 shows result that different self-awareness, sources of stress, income expenditure had an impact on manufacturing workers' pressure index $(\mathrm{p}<.000)$. In single factor analysis, we have the null hypothesis that means of questions are the same between groups. But we rejected null hypothesis because the P-values are all 0.05 which means questions in Figure 2 can significantly affect the pressure index.

\begin{tabular}{|l|c|c|c|c|}
\hline \multicolumn{1}{|c|}{ Questions } & Options & Quantity \% & Statistics & $\begin{array}{c}\boldsymbol{p} \text { - } \\
\text { Value }\end{array}$ \\
\hline & Yes & $\begin{array}{c}84.79 \% \\
(8566)\end{array}$ & \\
Q1: Have you ever had doubts about your worth & & $\begin{array}{c}14.79 \% \\
(1494)\end{array}$ & F=702.6 & $<.000$ \\
during the pandemic? & No & $\begin{array}{l}74.42 \% \\
(7519)\end{array}$ & F=2370 & $<.000$ \\
\hline $\begin{array}{l}\text { Q2: Is this Job important to you? Do you feel pressure } \\
\text { supporting your family? }\end{array}$ & Yes & & & \\
\hline
\end{tabular}




\begin{tabular}{|c|c|c|c|c|}
\hline & No & $\begin{array}{l}23.85 \% \\
(2410)\end{array}$ & & \\
\hline $\begin{array}{l}\text { Q4: Is your current salary sufficient for your family } \\
\text { or personal expenses? }\end{array}$ & $\begin{array}{l}\text { Yes } \\
\text { No }\end{array}$ & $\begin{array}{l}36.61 \% \\
(3699) \\
63.03 \% \\
(6368)\end{array}$ & $\mathrm{F}=1965$ & $<.000$ \\
\hline $\begin{array}{l}\text { Q5: Under the pandemic, did the company and the } \\
\text { government give you enough spiritual care? }\end{array}$ & $\begin{array}{c}\text { Yes } \\
\text { Not really } \\
\text { No }\end{array}$ & $\begin{array}{c}52.25 \% \\
(5279) \\
\\
33.02 \% \\
(3336) \\
\\
14.37 \% \\
(1452)\end{array}$ & $\mathrm{F}=251.9$ & $<.000$ \\
\hline $\begin{array}{l}\text { Q6: Are you stressed by the cost of health care for } \\
\text { you and your family }\end{array}$ & $\begin{array}{c}\text { Yes, I am very stressed } \\
\text { Not really } \\
\text { No }\end{array}$ & $\begin{array}{c}13.66 \% \\
(1380) \\
51.84 \% \\
(5237) \\
34.24 \% \\
(3459)\end{array}$ & $\mathrm{F}=412.7$ & $<.000$ \\
\hline $\begin{array}{l}\text { Q7: Under the pandemic, are you worried about the } \\
\text { risk of infection you are exposed to? }\end{array}$ & $\begin{array}{c}\text { Yes, I am very stressed } \\
\text { Not really } \\
\text { No }\end{array}$ & $\begin{array}{c}14.12 \% \\
(1427) \\
64.68 \% \\
(6535) \\
\\
20.88 \% \\
(2110)\end{array}$ & $F=412.7$ & $<.000$ \\
\hline $\begin{array}{l}\text { Q8: In addition to the existing basis, what additional } \\
\text { help do you expect the company and government to } \\
\text { provide? }\end{array}$ & $\begin{array}{l}\text { Financial help } \\
\text { Help in daily life } \\
\text { Psychological help }\end{array}$ & $\begin{array}{c}73.14 \% \\
(7389) \\
17.01 \% \\
(1719) \\
\\
9.44 \% \\
(954)\end{array}$ & $\mathrm{F}=49.89$ & $<.000$ \\
\hline $\begin{array}{l}\text { Q9: Has your work stress increased or decreased } \\
\text { under the pandemic? }\end{array}$ & $\begin{array}{l}\text { It increased } \\
\text { It didn't change } \\
\text { It decreased }\end{array}$ & $\begin{array}{c}69.49 \% \\
(7021) \\
\\
25.79 \% \\
(2606) \\
4.55 \% \\
(460)\end{array}$ & F-test & $<.000$ \\
\hline
\end{tabular}

Figure 2 Single-factor analysis of pressure on manufacturing workers Note: Only statistically significant results are listed.

\subsection{Multi-factor analysis of pressure on manufacturing workers.}

When the pressure index was used as a dependent variable, the single-factor analysis of the pressure index that Q1("No" as reference state), Q2("No" as reference state), Q4("No" as reference state), Q5("No" as reference state), Q6("No" as reference state), Q7("No" as reference state), Q8("Financial help" as reference state), Q9("Yes" as reference state ) were used as independent variables for multiple linear regression analysis. Figure 3 shows the contribution of different question responses to the pressure index. The $\mathrm{p}$-value of each question is less than
0.05 , meaning all variables are significant. The results showed that self-awareness, source of stress, income expenditures, needs and expectations were main factors in influencing the manufacturing workers' pressure index under pandemic COVID-19, which can explain $80.0 \%$ of the total variation.

The regression coefficients show the different influence of the aggregated responses of different questions, the option in positive number would increase worker's pressure index. Conversely, the negative number means this option can help decrease the pressure index. For instance, self-awareness affected workers' pressure. Therefore, when workers answered yes to the 
question about self-worth, their pressure index was higher. However, when workers answered yes to the question about salary sufficiency, their pressure index was lower.

\begin{tabular}{|l|c|c|c|c|}
\hline Dependent Variable & Regression Coefficient & $S E$ & $t$-test & $p$-value \\
\hline Constant & 1.146 & 0.2755 & 4.16 & $.000^{* * *}$ \\
\hline Q1 yes & 6.666 & 0.1151 & 57.895 & $.000^{* * *}$ \\
\hline Q2 yes & 9.809 & 0.09506 & 103.181 & $.000^{* * *}$ \\
\hline Q4 yes & -7.806 & 0.08513 & -91.696 & $.000^{* * *}$ \\
\hline Q5 slightly & -0.8557 & 0.1283 & -6.668 & $.000^{* * *}$ \\
\hline Q5 yes & -4.781 & 0.1212 & -39.451 & $.000 * * *$ \\
\hline Q6 slightly & 4.721 & 0.08984 & 52.553 & $.000^{* * *}$ \\
\hline Q6 yes & 6.841 & 0.1301 & 52.567 & $.000 * * *$ \\
\hline Q7 slightly & 3.759 & 0.103 & 36.49 & $.000 * * *$ \\
\hline Q7 yes & 6.931 & 0.14120 & 49.075 & $.000^{* * *}$ \\
\hline Q8 living & -1.171 & 0.11 & -10.646 & $.000 * * *$ \\
\hline Q8 mental & 3.031 & 0.138 & 21.967 & $.000 * * *$ \\
\hline Q9 increased & 7.504 & 0.1932 & 38.83 & $.000^{* * *}$ \\
\hline Q9 no & -1.167 & 0.204 & -5.72 & $.000 * * *$ \\
\hline
\end{tabular}

Figure 3 Multiple-factor analysis of pressure index of manufacturing workers. Note: $R^{2}=0.806$, adjusted $R^{2}=0.800, F=2887, p<.000$

\section{DISCUSSION OF THE RESULTS}

During the outbreaks of COVID-19 in China in February 2020, manufacturing factory workers experienced factory shut down and resumption. Although factories resumed production in the later months, many workers still weren't able to return to their jobs because of transportation and quarantine policies. Therefore, China's manufacturing workers have experienced extensive financial, social, and mental pressure on themselves and their families. In this study, these types of stress played a significant role.

Stress will affect a person's wellbeing. Physically, it can increase the risk of cardiovascular disease and exacerbating medical conditions such as asthma, diabetes and hypertension [4]; Psychologically, individuals might suffer depression, nervousness, or anxiety. When a person's wellbeing is affected, their family is likely to receive extra negative emotions or even have to undertake the related medical expenses, depending on their severity. What's more, stress also has an impact on ones' efficiency at work [5]. This means that stressful working conditions can lead to a decline in the productivity, which will then result in an income loss of the firm or even in the broader economy.

\subsection{Feeling of Lack of Self-Worth}

Based on our investigations and the surveys, it is observed that psychological burdens significantly increased stress levels for workers. This indicates that the feeling of lack of worth has negatively influenced their mental health. During the COVID-19, many factory workers faced unemployment. Meanwhile, they can't find the next job and can only stay at home. The "realitycheck", the feeling of powerlessness and the pressure to support the family will undoubtedly bring significant mental health problems to the workers, such as anxiety, sleep problems, depression, and may further exacerbate pre-existing mental health problems such as bipolar disorder.

This implies that unemployed workers may retain more negative emotions and anxiety during the pandemic, and therefore are more likely to have psychological problems. Recent research suggests that during later March 2020, at least 30-50 million migrant workers lost their jobs.

\subsection{Fear of Getting Infected}

Moreover, manufacturing workers work in factories, a public place that is usually crowded with poor system for ventilation. Therefore, they have a great possibility of 
being infected by the virus. This is undoubtedly a concern for those workers who had just returned to work.

During the first outbreak of the COVID-19 last year, at least 3000 nurses were infected in Wuhan, and $40 \%$ of these infections occurred at the hospital or their workplace. Having similar working conditions has pressured the manufacturing workers about the risk of getting infected at work, which could contribute to some mental health problems.

\subsection{Mental Support from Companies and the Government}

Another question contributing to the pressure index value in our survey is whether the company had given the workers enough mental care under the pandemic. According to the result, over half of the participants believe that they received enough mental support for them, which decreased the pressure index value in our model. For instance, on January 26th, 2020, the State Council of China informed all provinces to set up a new epidemic psychological assistance hotline. Each hotline has at least two seats and provides 24-hour hotline service [6]. According to an interview, there were about three or four hundred calls a day. In February, there were 216 calls a day at most [7]. Also, companies like Shandong Energy Group Co., Ltd, for example, set up a psychological counselling assistance system for employees and their families, including a psychological assistance hotline and expert consultation [8]. From the example of the Chinese government and companies, we can see that although Chinese employees are facing many sources of pressure under the epidemic situation, the government and companies taken practical measures to help and maintain the mental health of employees.

\subsection{Financial concerns}

Based on our investigations, we found out that the financial aspect also has a high impact on stress. When exploring this question in detail, the number of married people needs to be considered. Our data shows that $60 \%$ of the workers are married. Therefore, their job is strongly related to whether they can support themselves and their family, especially under the epidemic. According to the China National Bureau of Statistics, the GDP has decreased $6.8 \%$ over the year, whereas the unemployment rate increased 13\%. Up to June 2020, China's Purchasing Managers' Index, which is used to monitor macro-economic performance, has dropped below $50 \%$ to $49.1 \%$, indicating economic contraction [9]. These factors have aggravated the pressure of the manufacturing workers as there are too many uncertainties such as being unemployed during or after the pandemic or receiving reduced salaries during the period. On top of this, one of the difficulties for manufacturing workers is the necessity of being on-site, which means that they cannot work from home as other employees are able to. As a result, manufacturing workers faced a greater risk of unemployment than people from other occupations. Hence, they are likely to have a higher level of stress during Covid-19.

Moreover, healthcare is also considered as a financial concern, especially under the pandemic where many people are stressed by the cost of medical supplies such as masks, goggles or any medicine that helps to prevent the virus. Meanwhile, stress also comes from the panic of the possibility of getting coronavirus and being unable to pay for the treatment.

It is also found that financial support is the essential support that manufacturing workers would like to receive from their company and the government, especially under this global crisis. For instance, if the firm is able to support its workers economically without reducing their wages or firing them from the company, the pressure of the workers to support themselves and their family can then certainly decrease.

\section{IMPLICATIONS FOR GOVERNMENT AND COMPANIES}

It's essential for the society to have an intuitive understanding of the mental health state of manufacturing workers. Also, with limited resources, we have to find out the most effective way to reduce workers' stress according to the exact number and relative size of coefficient. Based on the data, we come up with suggestions on mental health and finance that we can give to the company and governments.

\subsection{Mental support}

Pay more attention to the mental health of workers. The data shows that most workers have high psychological pressure. Since manufacturing workers are one of marginal groups in the society, their mental health has not attracted the attention of most enterprises and the government yet. Therefore, we should take measures to protect employees' mental health actively.

For companies, firstly they can provide spiritual care to employees more often and incorporate the employee's mental state into the assessment of department's performance. Secondly, they can hire therapists who can call employees regularly, and express their condolences about workers' psychological situation, so that workers can receive care and guidance on mental health in time; Thirdly, it's recommendable that companies offer offline/online activities for group building to get employees to have a feeling of community and a chance to interact with others. Thus, workers would have more effective ways of relieving stress.

For governments, first, they should offer more help on the pandemic unemployment assistance, and reassure 
workers that they are able to get affordable health insurance through Insurance scheme. Besides, the local governments can provide a $24 / 7$ available psychological help hotline to help with people who suffer from emotional anxiety.

\subsection{Financial support}

\subsubsection{Implement active employment policy during the epidemic period}

Data shows that most people think that a job is important, since they have the burden of supporting their family. Regression coefficient shows that unemployment and family burden is a factor in increasing the pressure index based on the responses to our questionnaire. During the pandemic period, in order to protect workers' jobs, some companies have reduced layoffs by reducing the workload of workers. In the future, we suggest that the company further strengthen the protection of employment through the adjustment of workload and working hours, instead of mass downsizing.

\subsubsection{Implement more positive subsidies and protection policies}

According to the data, most people want to get economic subsidies, which can contribute to the reduction of stress value. For the governments, they could provide certain economic subsidies for workers' living and health expenses on the basis of the minimum wage standard. Also, cash subsidies are really effective. In Macao, the government has announced the establishment of a 10 billion MOP\$ special fund for antiepidemic assistance. For the local working people, the SAR Government will offer a skill-upgrading training course with a $\$ 5000$ allowance for each trainee. But in our point of view, the limited size of population and the developed economy can be the bedrock of such policies. Thus, the Chinese mainland government could learn from the practice of Macao government by adjusting it and taking more flexible measures.

For companies, it's also useful to provide more masks, hand sanitizer, and other epidemic prevention materials to its employees. These actions can not only provide life help, but also stabilize the staff mentality.

\section{LIMITATIONS OF THE RESEARCH}

Although the questionnaire provided linear and clear results, many elements of the research were left uncovered. The sample of the questionnaire was not divided in details since elements like department, age and gender have not been taken into consideration because of the limited length of the questionnaire.

Besides, the questionnaire was sent to the employees by high-level executives of the company, so the authenticity of the results may be affected. However, this is the only way for us to reach a large number of employees.

Last but not least, as the peak of the pandemic in China has been gone for a while, the accuracy of the research will not be as high as the time period when COVID 19 was at its worst. Moreover, a few of the circumstances then might not comply with the current situation, thus undermining the practical value of this research a little bit.

However, despite these limitations, we still believe that the implications that this research has revealed are valuable in post-pandemic decision making processes of both the company and the government.

\section{CONCLUSION}

The COVID-19 outbreak in China in early 2020 has had great impact on people, and greatly challenged the public health system in China. During this period, the manufacturing workers are affected socially, financially and psychologically. Our research results suggest that factors like breadwinning, daily expenses, potential healthcare cost and expectations of the workers towards the firm and governments, are all causes which affect their stress level. At the same time, these forces affect the company as well as the broader economy. Moreover, the mental stress which comes from fear of unemployment, the possibility of infection in the workplace, quarantine and factory shutdown, and the pressure to support their families all contribute to the mental health problems of China's manufacturing workers.

As shown in the above chapters, companies and the government did put some efforts into supporting the mental status of these workers. However, these are not sufficient. In order to tackle this problem, this research investigates the mental and social status of China's manufacturing workers under the COVID-19 pandemic, analyzes the causes of their mental stress, and provides evidence-based suggestions for future improvements when it comes to providing better mental care of these workers.

\section{REFERENCES}

[1] Lai, Chih-Cheng, et al. "Severe Acute Respiratory Syndrome Coronavirus 2 (SARS-CoV-2) and Coronavirus Disease-2019 (COVID-19): The Epidemic and the Challenges". International Journal of Antimicrobial Agents, vol. 55, no. 3, March 2020, p. 105924-1.

[2] Jin, Shushu. "Concerned about the Resumption of Manufacturing in Mainland China." 12 February 2021,https://home.kpmg/cn/zh/home/insights/2020/ 02/rebooting-manufacturing-in-mainlandchina.html. 
[3] Maxwell, Joseph. "Designing a Qualitative Study". The SAGE Handbook of Applied Social Research Methods, by Leonard Bickman and Debra Rog, SAGE Publications, Inc., 2009, pp. 214-53.

[4] Yvette C. Terrie, BSPharm, RPh. "The Impact of Stress on Health: Learning to Cope". Pharmacy Times, $10 \quad$ Apr. 2020, https://www.pharmacytimes.com/view/stress-0410.

[5] Godin, Isabelle, and France Kittel. "Differential Economic Stability and Psychosocial Stress at Work: Associations with Psychosomatic Complaints and Absenteeism." Social Science \& Medicine, vol. 58, no. 8, April 2004, pp. 1543-53.

[6] State Council: All Localities Should Set up Hotlines for Psychological Assistance in Response to the Epidemic, Free 24-Hour Service. 3 February 2020 https://baijiahao.baidu.com/ $\underline{\mathrm{s} ? \mathrm{id}=1657480332913444840 \& \mathrm{wfr}=\text { spider } \& \text { for }=\mathrm{pc}}$

[7] Psychological Assistance Hotline Story during the Epidemic.11 February 2020. https://baijiahao.baidu.com/s?id=16635528259190 $65643 \&$ wfr $=$ spider $\&$ for $=p c$

[8] Psychological Assistance Hotline for Employees during the Epidemic Prevention and Control Period. 11 February 2020, http://www.ykjt.cn/xwzx/2020$\underline{02 / 11 / \text { content } 1056732 . \mathrm{html}}$

[9] Yanhong, Qiao. "Focus: China's Manufacturing Industry Has Recovered but Employment Has Not Improved Significantly. How to Give SMEs 'Reassurance?" Reuters, 02 July 2020, https://www.reuters.com/article/china-plant-pmijob-smb-0702-idCNKBS2430KW. 